\title{
College Teachers' Soft Ability Indicator System and Measuring Methods
}

\author{
Fen Sun 1 , Yinqiu $\mathrm{Ma}^{2 *}$ \\ ${ }^{1}$ School of Business, Nanjing University of Information Science \& Technology, Nanjing, China \\ ${ }^{2}$ Business School, Nanjing Normal University, Nanjing, China \\ Email: *watianqiuzi@126.com
}

How to cite this paper: Sun, F. and Ma, Y.Q. (2019) College Teachers' Soft Ability Indicator System and Measuring Methods. Journal of Human Resource and Sustainability Studies, 7, 277-283.

https://doi.org/10.4236/jhrss.2019.72017

Received: May 22, 2019

Accepted: June 18, 2019

Published: June 21, 2019

Copyright $\odot 2019$ by author(s) and Scientific Research Publishing Inc. This work is licensed under the Creative Commons Attribution International License (CC BY 4.0).

http://creativecommons.org/licenses/by/4.0/

\begin{abstract}
The concept and features of college teachers' soft abilities are defined. The features of College Teachers' Soft Ability are: not easy to train and develop; talent's deep characteristic; capable of effectively predict high working performance. The method to establish the Soft Ability indicator system is: to be sure about job requirements on hard abilities involving knowledge and technique via college teachers' job analysis; then to use behavioral event interview to determine the essential condition of soft abilities related to high performance. The method to measure College Teachers' Soft Abilities in recruitment and selection is to firstly change soft ability as specific work behavior, and then make measurement by methods of employment interview, evaluation and behavior observation.
\end{abstract}

\section{Keywords}

College Teachers' Competency, Soft Ability, Indicator System, Measuring Method

\section{Introduction}

Traditional talent recruitment and selection emphasize on testing job hunters' intelligence, so stock of human capital such as knowledge and education background receives high attention, while Talent Quality Soft Ability such as motivation, attitude and values has been neglecting by evaluators for so long due to its implicitness. However, based on McClelland's (1973) [1] view, as Talent Quality Soft Ability directly relates to high performance, it's necessary to pay attention to it, and study on its composition, features and measuring methods.

${ }^{\star}$ Corresponding author. 


\section{Concept, Composition and Indicator System of College Teachers' Soft Ability}

\subsection{Conception Definition of College Teachers' Competency and Soft Ability}

Competency refers to the quality necessary for a talent to finish a specific job, realize organizational performance; it's combination of various qualities of talents.

In the competency system, we name some competencies as "hard ability", such as education background, knowledge and skills, qualification certificates, languages etc. Knowledge is the main part of competencies necessary for college teachers to finish their jobs. Skills are the ability to finish an acquirable mechanical task, such as teaching skills. Suck kind of competency is reflection of talents' stock of human capital, which can be gained through education and trainings.

We name some other competencies as soft abilities. According to Liu Xuefang (2006) [2], they are "personal characteristics that are able to distinguish different performance levels in a specific post and organizational environment". The soft abilities of college teachers are the sum of all the potential characteristics of teachers with excellent performance, which is different from those of ordinary teachers, in the areas such as teaching, scientific research, talents training, and public services.

\subsection{Composition of College Teachers' Soft Ability}

McClelland (1973) [1] points that motivation, ability, personal characteristics, attitude and values are the invisible factors of competency model. Based on the research, I conclude that the composition of college teachers' soft abilities includes:

Motivation: college teachers' driving ability, willingness and even aspiration to realize his goal.

Ability: the capability college teacher needs to finish a task, such as communication capability, mathematical ability, inferential and problem-solving capability.

Personal characteristics: a college teacher's willingness or characteristic of adapting the environment. Willingness includes such as that of bearing drabness, overworking and teamworking. Characteristics such as witty, decisive, caring, objective and owns work ethics.

Attitude and values: whether conforms with college value, whether accept college vision and philosophy, and be able to blend in college culture.

\subsection{Competency Models of College Teachers}

Different posts require different competency indicator systems. Even the same post may have different competency indicator system requirements in different environment. There are already some researches on the college teachers' competency model. 
The model of competency for international teachers are suggested by Zhang Lihui (2008) [3] contains four dimensions in sixteen level-2 items: 1) the dimension of personality including sense of fairness, sense of duty, respect for teacher's career, interest in Chinese culture; 2) the dimension of temperament including self-confidence, optimism, initiative, patience and sense of service; 3 ) the dimensions of general abilities including thinking abilities, interpersonal understanding, team cooperation and self-control; and 4) the dimension of professional ability including professional level, theories on teaching, teaching organization and strategies of teaching.

The model of competent qualifications for research-oriented college teachers as introduced by Xu Anquo (2012) [4] is composed of such layers as basic competency of a college teacher, teaching ability professional expertise, scientific research capacities.

\subsection{Comparison of Soft Ability and Competency}

In the 1970's, McClelland (1973) [1] was the first one to propose competency with the idea that it has positive correlation with work performance. Spencer (1993) [5] defined competency as "potential personal characteristic which can distinguish outstanding achievers and mediocre individuals in a certain job (or organization, culture), it may include motivation, material, self-image, attitude or values, and knowledge, congnition or behavioral skills in some field, that is any personal characteristic can be measured or calculated reliably then can make clear distinction between outstanding and common performance". According to Shi Kan (2006) [6], "Boyatzis summarized excellent managers Competency Collection in 1982 after making various literature retrievals and empirical researches, and gives systematic introduction in his magnum opus Competent Managers". Spencer \& Spencer (1993) [5] made systematic research on more then 200 kinds of jobs in industries of science \& technology, education, manufacture, sales, service, government organizations, military organization, medical care and religious organizations, and finally constructed industry model framework for people in 5 common industries including professionals, salesmen, community servicers, managers and entrepreneurs, and formed competency model database.

There are many researches on competency model for specific posts in China. Competency model is also applied in many fields concerning human resource management, such as Xu Feng (2012) [7] constructed human resource performance management system from the angle of competency model; Pan Xiaoling (2011) [8] researched on construction of competency-based human resource management model and value measurement; Zhao Shuming (2007) [9] made researched on human resource management that based on competency model.

To sum up, the hard abilities such as education background, knowledge and skills, qualification certificates, languages are not always related to high performance and they are parts of competency system. Soft ability is certain related to high performance, it belongs to competency. That is to say, Soft Ability is com- 
petency, while some competency factors in competency model is not soft ability.

\section{Features of College Teachers' Soft Ability}

Why some competency is call "soft ability"? What feature that is different from that of "hard ability"?

\subsection{It's Relatively Hard to Train and Develop}

I think hard ability such as knowledge and skills, qualification certificates, languages can be acquired via training and developing, while it's relatively hard to develop soft ability.

\subsection{It Is Talents' Deep Characteristic}

Competency hard ability is talents' superficial characteristic, and it's at the surface of iceberg competency model, so it's easy to observe and measure.

While Talent Quality Soft Ability displays people's behavior characteristic and mode of thinking, it's stable and lasting; it's talents' deep characteristic that is hidden under iceberg model, thus it's difficult to be observed and measured.

\subsection{Effectively Predict High Working Performance}

Talent Quality Soft Ability is the competency can effectively predict high working performance. In China, Zhao Shuming (2007) [9] discovered some competency can predict working performance of managers of different levels, while hard ability is not found to be certainly related to high performances. McClelland (1973) [1] "proved that traditional intelligence test results have small correlation with job success factors by listing a large number of research results and data".

\section{Methods to Determine College Teachers' Soft Ability Indicator System}

\subsection{Determine Basic Outline of Hard Abilities Related to Teachers' Jobs through Work Analysis}

Work analysis is precondition and basis of recruitment and selection, and through the analysis we may get requirements on knowledge and skills, qualifications, and then determine selection standards. As precondition of recruitment and selection, traditional work analysis aims at helping employers to find suitable employees to realize person-position matching, rather than finding employees with high performance.

Besides work content and background information, work analysis must define the essential condition for specific posts. We think that traditional work analysis is useful and effective in determining basic outline of hard abilities, that is the minimum requirement for specific posts, for instance determining needed knowledge, skills and certificates for college teachers' job performance. 


\subsection{Determine Soft Ability Related to Teachers' Work through Behavioral Event Interview}

Relatively speaking, it's difficult to determine the essential conditions of soft ability related to specific posts. What methods will be adopted? McClelland (1973) [1] used "Behavioral Event Interview" to raise competency testing rather than intelligence. In China, Shi Kan (2002) [10] also applied the method of "Behavioral Event Interview". Behavioral Event Interview emphasized on discovering competency factors that had been caused high performance from things happened. Song Chanrong (2003) [11] concluded that "tools used for building competency model mainly include: direct observation method, work analysis interview (include fact-to-face interview, telephone interview, one-to-one interview or focus group interview), expert group discussion, key events technical, questionnaires (work questionnaire and list survey, post analysis questionnaire $\mathrm{PAQ}$ ), functional job analysis (FJA), job description analysis, referring to existing competency model or expert system data etc.". Since "the most effective and generally accepted method is Behavioral Event Interview (BEI) proposed by American psychologist McClelland through combing key event method and thematic apperception test" Shi Kan (2006) [6], this paper mainly introduces this method.

Behavioral Event Interview (BEI) is to discover behavior characteristics and psychological property of persons with high performance in key events, and finally conclude the competency. BEI adopts open behavior to review exploring technique, it enables interviewees to describe the top 3 things which are most successful and most unsuccessful respectively in their career, then and make a reports in detail for what happened exactly. The report includes: what caused such situation? Who were involved? What did they think then? And their feelings? What did they want to achieve then, but what did they do actually? And the results? Then interviewers analyze all the interview content to determine what competency interviewees display. The competency model of a task is determined by comparing different competency characteristics of outstanding achiever and mediocre individual. Behavioral Event Interview (BEI) is limited due to it cannot provide complete description of job qualifications and the outline of minimum qualifications.

In conclusion, I think that a better method should firstly describe job duties, work task, working background and minimum, basic qualification through work analysis so as to determine the requirement on hard ability such as knowledge, skills, then apply Behavioral Event Interview (BEI) to determine the essential conditions in soft ability related to high performance this job.

\section{Should Be Used in Measuring of College Teachers' Job Hunters' Soft Ability in Recruitment and Selection}

\subsection{Methods to Measure Job Hunters' Hard Ability in College Teachers' Recruitment and Selection}

We may store job-hunters' "hard ability" such as education background, qualifi- 
cation certificates in computer system, once there is job vacancy, we can easily find the right talents via searching the data. Moreover, this qualification condition can be measured rapidly through filling in resumes and job application forms.

I think the "hard ability"-knowledge can be tested through interview, examinations and tests; while working skills can be tested through job sample test, requiring job hunters to finish vacant job responsibilities on site.

\subsection{Methods to Measure College Teachers' Job Hunters' Soft Ability in Recruitment and Selection}

\subsubsection{Define Soft Ability as Specific Work Behavior}

We mainly test for behavior features related to competency performance in different environment. Whether it will be successful or unsuccessful in finishing a specific job, some specific work behavior determines this. Therefore, it is the specific work behavior in some specific job that we shall tested in recruitment and selection. So soft ability should be applied in recruitment and selection, competency should be defined as specific work behavior.

\subsubsection{Combining Employment Interview, Evaluation and Behavior Observation}

Talent Quality Soft Ability can be properly measured through combination of employment interview, evaluation and behavior observation.

Employment interview is to inspect one attitude, values, philosophy and interests etc. Behavior description information during employment interview is very useful as it asks interviewees to describe what did they do in the past and what will they do in upcoming new but similar working situation.

Evaluation includes leaderless group discussion, management game, hanaper, report and performance; To my mind, its efficiency is that it contains work sample test through which can evaluate whether employees have ideal behavior in scene practice and job simulation, and people may use various evaluation techniques for various purposes.

According to Klayman (2009) [12], "Behavior observation includes all behavior required by successful performance in a specific job, and is evaluated by assessors. The assessors will evaluate employees' work performance by pointing out the frequency of their behaviors. A 5-score evaluation form is divided into 'seldom or never (1) to always (5)'. We get the total score by adding the scores gained for each item, the higher total score is, the more likely the employee behaves as expected."

\section{Conclusion}

Finally, I consider: employment interview, evaluation can display job-hunters' Talent Quality Soft Ability, while we should realize relevant records and quantification through behavior observation form; the combination of the three can effectively measure Talent Quality Soft Ability. 


\section{Fund Program}

The National Social Science Fund of China under Grant 15BGL107.

\section{Conflicts of Interest}

The authors declare no conflicts of interest.

\section{References}

[1] McClelland, D. (1973) Testing for Competence Rather than for Intelligence. American Psychologist, 28, 1-14. https://doi.org/10.1037/h0034092

[2] Liu, X.F. (2006) Competency Model Building for Family Enterprise Successors-An Empirical Research. Management World, 5, 96-106.

[3] Zhang, L.H., Zhong, S.Y. and Liu, Z.L. (2018) Exploring the Competency Model of Foreign Teachers in the Background of Sino-Foreign Cooperation in Running Schools. Higher Education Exploration, 6, 17-21.

[4] Xuan, G., Ye, L. and Guo, M. (2012) Research on Building the Competency Model of Research University Teachers. Journal of Higher Education Research in China, 12, 65-68.

[5] Spencer, L.M. and Spencer, S.M. (1993) Competence at Work: Models for Superior Performance. John Wiley \& Sons Press, New York.

[6] Shi, K. (2006) Human Resource Development Based on Competency Model. Advances in Psychological Science, 14, 586-595.

[7] Xu F. (2012) The Construction of HR Performance Management System: Based on the Competency Model. Human Resources, 1, 68-71.

[8] Pan, X.L. (2011) The Construction and Value Measurement Estimate of Human Resources Model Based on Competency. Human Resources, 8, 72-75.

[9] Zhao, S.M. and Du, J. (2007) Human Resource Management Based on Competency Model. Economic Management, 6, 16-22.

[10] Shi, K. (2002) Assessment on Competency Model of Senior Managers. Acta Psychologica Sinica, 3, 306-311.

[11] Song, C.R. (2003) Hierarchical System and the Controlling in Firms. Economic Issues in China, 6, 90-106.

[12] Klayman (2009) Human Resource Management: Tools for Gaining Competitive Advantages. China Machine Press, Beijing. 